\title{
SYNTHESIS OF GLYCEROL TRILEVULINATE ESTER: EFFECT OF REACTION PARAMETERS
}

\author{
NIK SITI MARIAM NEK MAT DIN*; YEONG SHOOT KIAN*; HOONG SENG SOI*; \\ ARNIZA MOHD ZAN*; SRIHANUM ADNAN* and RAHIMI M YUSOP**
}

\begin{abstract}
Derivatisation of glycerol (Gly) with levulinic acid (LA) to produce glycerol trilevulinate (Gt-LE) was studied. The reaction parameters affecting synthesis of Gt-LE were investigated. Catalytic and non-catalytic reactions between Gly and LA were carried out. Effects of reaction time and temperature on non-catalytic reaction were observed. Conversely, for catalysed reaction, reaction parameters studied were type of catalyst, mole ratio, catalyst loading and reaction time. Result analysis indicated that for the catalyst-free reaction, increment of reaction time and temperature will further reduce the acid value of reaction product. On the other hand, for catalytic reaction, $\mathrm{p}-\mathrm{Ts} \mathrm{OH}$ accelerated the reaction much faster than montmorillonite, Amberlyst-15 or Amberlyst-46. Result analysis also showed that the best mole ratio and catalyst loading to obtain high composition of Gt-LE without having to go through cumbersome purifying process was 1:6 with $8 \%$ catalyst loading. For reaction conducted with mole ratio of 1:6 (Gly:LA), the optimum reaction time and temperature was found to be $8 \mathrm{hr}$ and $140^{\circ} \mathrm{C}$, respectively, in which GC analysis showed that product contained about $84.5 \%$ of Gt-LE.
\end{abstract}

Keywords: glycerol, levulinic acid, biodiesel by-product, levulinate ester.

Date received: 15 October 2018; Sent for revision: 15 October 2018; Received in final form: 29 March 2019; Accepted: 30 September 2019.

\section{INTRODUCTION}

Most of the carbon-based compounds currently manufactured by the chemical industry are derived from petroleum. The rising cost and dwindling supply of mineral oil has prompted researchers worldwide to divert attention to possible routes in making chemicals, fuels, and solvents from biomass. The situation also initiated an array of research efforts in converting glycerol (Gly) to value-added platform molecules such as glycerol carbonate,

\footnotetext{
Malaysian Palm Oil Board, 6 Persiaran Institusi, Bandar Baru Bangi, 43000 Kajang,

Selangor, Malaysia.

E-mail: nsmariam@mpob.gov.my

** School of Chemical Science and Food Technology,

Faculty of Science and Technology,

Universiti Kebangsaan Malaysia, 43600 Bangi,

Selangor, Malaysia.
}

1,3-propanediol, epichlorohydrin, acrolein and few other chemicals (Kenar, 2007).

Currently, Malaysia is the second largest producer of palm oil in the world, which accounted for $40 \%$ of total global demand for crude palm oil $(\mathrm{CPO})$ and this strategically position the nation as a significant player in the global dynamics of biodiesel production (Lam et al., 2009). The global biodiesel production in 2017 was 35.19 million tonnes and $30.6 \%$ was palm biodiesel ( Kushairi et al., 2018). In Malaysia, $720410 \mathrm{t}$ of palm biodiesel were produced in 2016 of which $235291 \mathrm{t}$ were exported mainly to the European Union (EU), $358586 \mathrm{t}$ were used for local B7 blending and the remaining $126533 \mathrm{t}$ were used as oleochemicals (Unnithan, 2018; Kushairi et al., 2018).

Glycerol is the major by-product of biodiesel production. One tonne of biodiesel yields about $110 \mathrm{~kg}$ of crude glycerol or about $100 \mathrm{~kg}$ of 
pure glycerol. Finding new uses of glycerol besides the typical consumptions is one of the crucial steps to be taken in order to ensure the sustainability and continuance of the biodiesel industry.

The palm oil industry generates a large quantity of oil palm biomass. It was estimated that 67.69 million tonnes of palm oil mill effluent (POME) and 22.22 million tonnes of empty fruit bunches (EFB) were generated in 2017 (Kushairi et al., 2018). Levulinic acid (LA) is another value-added chemical that can be obtained from lignocellulosic biomass. LA and its derivatives have been used as building blocks for the preparation of many types of new compound that includes levulinate esters, $\alpha$-valerolactone, acrylic acid, 1,4-pentanediol, $\beta$-acetylacrylic acid, $\alpha$-angelica lactone, 2-methyl THF, and $\delta$-amino levulinic acid (Bozell et al., 2000; Rackemann and Doherty, 2011; Girisuta and Heeres, 2017). These new compounds found uses in many applications such as in biofuel, polymers and plasticisers. Besides that several researchers have reported on extraction of LA from oil palm biomass such as from frond (Khan et al., 2018), empty fruit bunch (Ramli and Amin, 2014) and mesocarp fibre (Tiong et al., 2018). Gly and LA have been known as top value-added chemicals from biomass by scientists (Werpy et al., 2004).

LA and its derivatives have been used as building blocks for the preparation of many types of polymers. The LA derivatives include levulinate esters, c-valerolactone, acrylic acid, 1,4-pentanediol, $\beta$-acetylacrylic acid, $\alpha$-angelica lactone, and 2-methyl THF (Girisuta and Heeres, 2017). and LA can form oligo (levulinic acid-co-glycerol) by using acid catalyst as described by (Amarasekara and Hawkins, 2011). These levulinic acid-glycerol oligomers may possess three types of terminal units: keto, glycerol-ketal, and glycerol-ester in the form of linear oligomers (Figure 1). These oligomers were reported to be useful as a plasticiser, and as a raw material for block co-polyester synthesis.

This present work focuses on the esterification of glycerol with LA to produce Gt-LE. This compound ideally will have three ketone (tri-ketones) and three ester functionalities (Figure 2).

Triketones derivatives also have long been known for their extensive application as biologically active substances. For instance, nitisinone and sethoxydim (Figure 3) has been used as a therapeutic agent for the treatment of tyrosinaemia (Lindstedt et al., 1992). Other than that, triketone derivatives such as sulcotrione and mesotrione (Figure $3 b$ ) are examples of commercial triketones that found uses as bleaching herbicide. The bleaching herbicide is used to impede essential compound that promote formation of crucial biochemical that is important in normal growth of plant (Da-Wei et al., 2015).

Thus, comprehending the synthesis process and structural development of this multipurpose compound can be considered crucial for further developments of this important versatile molecule. Development of this molecule also indirectly will catalyse the expansion of oleochemical industry, where oleochemical industry serves as the backbone of many end-market industries such as agriculture, automotive, construction, household<smiles>CC(=O)CCC(=O)O</smiles>

Levulinic acid<smiles>OCC(O)CO</smiles>

Glycerol

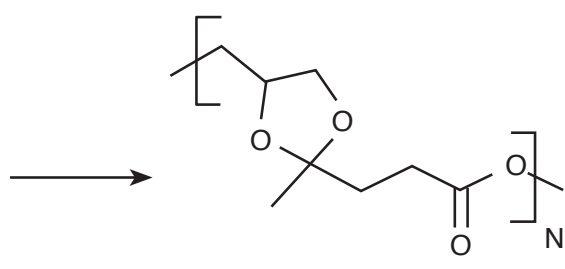

Oligo (levulinic acid-co-glycerol)

Figure 1. Synthesis of oligo (levulinic acid-co-glycerol).

Reaction between Gly and LA has been reported by several researchers recently to give several types of structures with different targeted usage. As an example, Bloom (2007) has reported on synthesis of glycerol trilevulinate (Gt-LE) as part of the content of patent US 2010/0216915 A1. His study revealed that Gt-LE has a potential to be used as plasticiser and coalescent solvents in polymer compositions. In the patent, comparative data shows that paint formulations containing Gt-LE have improved resistance to scrub (resistance towards abrasion caused by a brush, sponge, or other means) (ASTM, 2017), block (the condition wherein coated surfaces adhere to each other (ASTM, 2016) and freeze-thaw. Other than forming Gt-LE, the reaction between Gly

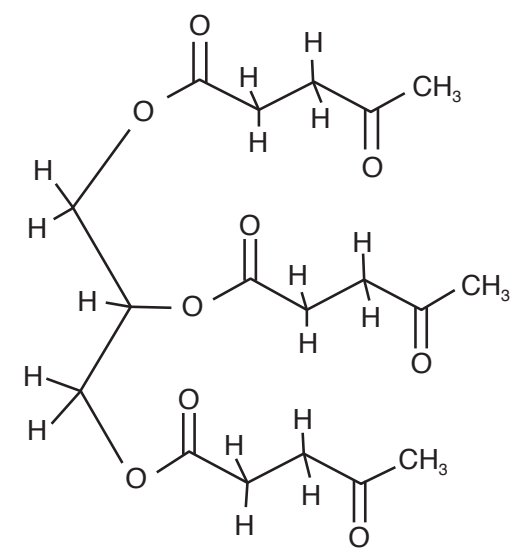

Figure 2. Structure of Gt-LE of glycerol and levulinic acid. 
<smiles>CCC/C(=N\OCC)C1=C(O)CC(CC(C)[Si]C)CC1=O</smiles>

Sethoxydim<smiles>O=C1CCCC(O)=C1C(=O)c1ccc(C(F)(F)F)cc1[N+](=O)[O-]</smiles>

Nitisinone

Figure 3a. Structure of sethoxydim and nitisinone.<smiles>CS(=O)(=O)c1ccc(C(=O)C2=C(O)CCCC2=O)c(Cl)c1</smiles>

Sulcotrione<smiles>CS(=O)(=O)c1ccc(C(=O)C2=C(O)CCCC2=O)c([N+](=O)[O-])c1</smiles>

Mesotrione

Figure 3b. Structure of sulcotrione and mesotrione.

and consumer products (Kushairi et al., 2017). Therefore, the objective of this article is to report the reaction parameters affecting the synthesis of Gt-LE from Gly and LA.

\section{MATERIALS AND METHODS}

\section{Materials}

Refined Gly (99.8\% purity) was obtained from Fluka, USA. LA and $p$-toluene sulphonic acid $(p-\mathrm{TsOH})$ were obtained from Sigma Aldrich, USA. Montmorillonite was purchased from Merck, Germany. All the reagents were used without further purification.

\section{Methods}

Synthesis of Gt-LE ester. Reactions were carried out in $250 \mathrm{ml}$ two-necked round bottom flask equipped with a magnetic stirrer, a Dean and Stark apparatus attached to a condenser to trap and monitor water discharged from the reaction. Gly, LA, catalyst and toluene were placed in the flask and heated to the desired temperature. For catalyst-free reaction, only the raw material and solvent were used. An oil bath equipped with thermometer was used to maintain the reaction temperature. The amount of reagents was calculated according to the desired molar ratio for each reaction. The reaction was monitored through acid value and thin-layer chromatography analysis. After the reaction was completed, the crude product was analysed using gas chromatography (GC), ${ }^{1} \mathrm{H}$ and ${ }^{13} \mathrm{C}$ nuclear magnetic resonance (NMR) spectroscopy and Fourier transform infrared (FTIR) spectroscopy.

Purification of crude Gt-LE. After the reaction was completed, the sample was washed with saturated sodium carbonate in order to neutralise the acid catalyst. This was followed by addition of toluene to extract Gt-LE and addition of water to remove unreacted Gly and LA. These steps were repeated several times in a separating funnel. After the washing steps were completed, the non-aqueous layer was concentrated under vacuum using rotorevaporator to obtain the highest possible purity of Gt-LE.

\section{Analysis and Characterisation of Gt-LE Ester}

FTIR. A convenient analytical method for determining the functional groups of the Gt-LE was conducted using Spectrum 100 FT-IR Spectrometer Perkin Elmer. Samples were scanned between 4000 $650 \mathrm{~cm}^{-1}$ wave numbers.

GC analysis. Quantitative analysis of the reaction mixture was conducted using GC. The GC (Agilent System 6890N Network GC System) was equipped with a ZB-5HT INFERNO (30 m x $250 \mu \mathrm{m} \times 0.2 \mu \mathrm{m})$ capillary column and flame ionisation detector. The following temperature programming was used: 
oven temperature, $80^{\circ} \mathrm{C}$; initial temperature, $80^{\circ} \mathrm{C}$; heating rate at $10^{\circ} \mathrm{C} \mathrm{min}^{-1}$; final temperature, $315^{\circ} \mathrm{C}$; injector temperature, $300^{\circ} \mathrm{C}$; detector temperature, $325^{\circ} \mathrm{C}$; carrier gas, helium at $40.0 \mathrm{ml} \mathrm{min}{ }^{-1}$. The composition of products was determined according to the percent area under the respective peak in the GC chromatogram.

${ }^{1} \mathrm{H}$ and ${ }^{13} \mathrm{C}$ NMR analysis. Proton $\left({ }^{1} \mathrm{H}\right)$ and carbon $\left({ }^{13} \mathrm{C}\right)$ NMR spectroscopy were recorded on JOEL JNM-ECZ600R at $600 \mathrm{MHz}$ and $150 \mathrm{MHz}$ respectively at $298 \mathrm{~K}$ with approximately $10 \% \mathrm{w} / \mathrm{v}$ solutions in deuterated NMR solvents. Chemical shifts are quoted in ppm relative to internal standard tetramethylsilane (TMS) and reference to the residual solvent. All coupling constant are quoted in hertz $(\mathrm{Hz})$. The ${ }^{1} \mathrm{H}$ and ${ }^{13} \mathrm{C}$ NMR assignments were routinely confirmed by ${ }^{1} \mathrm{H}-{ }^{1} \mathrm{H}$ (COSY) and ${ }^{1} \mathrm{H}-{ }^{13} \mathrm{C}$ (HMQC) data.

Acid value determination. Acid value (AV) of GtLE was analysed according to the AOCS Official Methods and Recommended Practices of the American Oil Chemists' Society, Acid Value (Te 1a-64).

\section{RESULTS AND DISCUSSION}

\section{Catalyst Free Reaction: Prescreening of Reaction Time and Temperature}

Results in Figure 4 revealed that the AV decreased as the reaction temperature increased as predicted. AV also decreased as the reaction time increased for all reaction temperature studied. In general, as reported by Dange and Rathod (2017), weak catalytic activity requires high reaction temperatures and long reaction time; result from this theory also can be implemented to the catalyst-free reaction. Other than that, as predicted and in parallel with findings in referred literatures, this result demonstrated that the reaction rate increased with the increment of reaction temperature and time, therefore will increase the rate of glycerol-ester of LA formation (Ashworth et al., 2012; Go et al., 2014). Table 1 shows the composition of glycerol monolevulinate ester (Gm-LE), glycerol di-levulinate ester (Gd-LE) and Gly tri-levulinate ester (Gt-LE) in the reaction products as analysed by GC. The results showed that, the percent composition of Gm-LE, Gd-LE and Gt-LE were higher when the reaction temperature was increased. For reaction conducted at $180^{\circ} \mathrm{C}$, the composition of Gm-LE, Gd-LE and Gt-LE did not show any increment as compared to reaction conducted at lower temperature. Formation of compound with larger molecular weight was observed for reaction conducted at $180^{\circ} \mathrm{C}$. For study at $180^{\circ} \mathrm{C}$, the reaction was terminated at 32 $\mathrm{hr}$ because beyond that time the reaction product charred. Studies on catalyst-free reactions revealed that the esterification reaction between Gly and LA to obtain high composition of Gt-LE is affected by reaction time and temperature, which determine the cost effectiveness of the process. Several studies on non-catalytic esterification reactions (Ashworth et al., 2012; Sanz et al., 2002; Pöpken et al., 2000) showed that self-catalysed esterification of short chain mono-carboxylic acid such as maleic acid, lactic acid and acetic acid with methanol was found to be catalysed by proton ion $\left(\mathrm{H}^{+}\right)$generated by the ionisation of the corresponding acid.

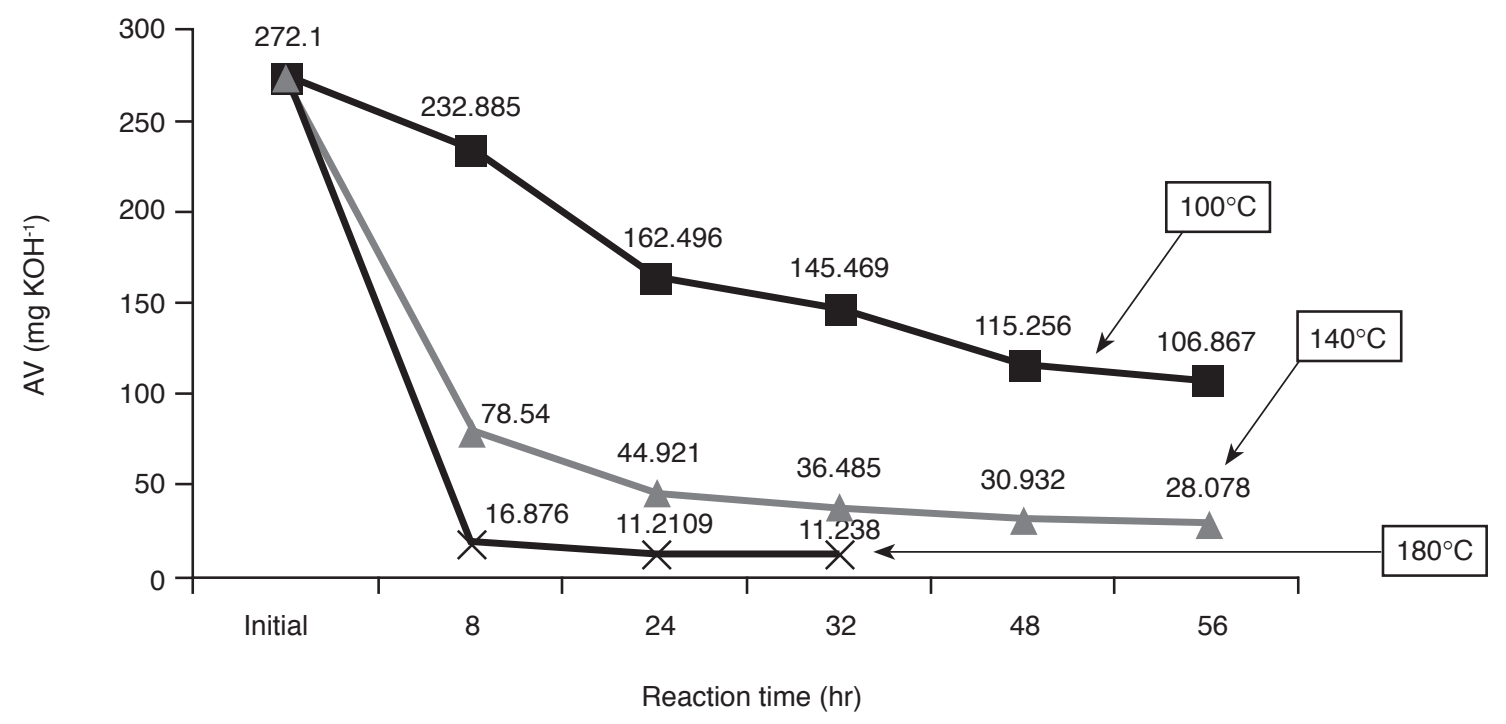

Figure 4. Acid value of the samples at 8,24,32, 48 and $56 \mathrm{hr}$ of reaction for each stated reaction temperature. The duration of reaction was kept at $56 \mathrm{hr}$ except for reaction which was conducted at $180^{\circ} \mathrm{C}$ which was terminated at $32 \mathrm{hr}$. 
TABLE 1. OPTIMISATION OF CATALYST-FREE REACTION: EFFECT OF REACTION TEMPERATURE

\begin{tabular}{|c|c|c|c|c|}
\hline \multirow[t]{2}{*}{$\begin{array}{l}\text { Retention } \\
\text { time (min) }\end{array}$} & \multicolumn{3}{|c|}{$\begin{array}{c}\text { Area } \% \\
\text { (reaction at } 8 \mathrm{hr} \text { ) }\end{array}$} & \multirow[t]{2}{*}{ Remarks } \\
\hline & $100^{\circ} \mathrm{C}$ & $140^{\circ} \mathrm{C}$ & $180^{\circ} \mathrm{C}$ & \\
\hline $12-13$ & 35.9 & 25.62 & 19.13 & Gm-LE \\
\hline $17-18$ & 13.26 & 21.62 & 22.04 & Gd-LE \\
\hline 21 & 6.24 & 15.9 & 20.8 & Gt-LE \\
\hline Total ester & 55.4 & 63.14 & 61.97 & - \\
\hline $24 \& 29$ & 2.46 & 13.51 & 24.17 & $\begin{array}{l}\text { Larger molecular } \\
\text { weight compound }\end{array}$ \\
\hline
\end{tabular}

Note: Gm-LE - glycerol mono-levulinate.

Gd-LE - glycerol di-levulinate.

Gt-LE - glycerol tri-levulinate.

\section{Catalysed Reaction}

Effects of catalyst compound. In this study, four different acid catalysts ( $p$ - $\mathrm{TsOH}$, amberlyst A-46, amberlyst A-15, and montmorillonite) were used. Table 2 shows the AV of product and amount of water collected at the end of reaction for each catalyst. The results revealed that $p$ - $\mathrm{TsOH}$ was the best catalyst for the reaction followed by Amberlyst-15, Amberlyst-46 and montmorillonite. Lowest AV and highest water collected in Dean Stark apparatus was obtained when $p$ - $\mathrm{TsOH}$ was used as catalyst. The $p$ - $\mathrm{TsOH}$, a heterogeneous catalyst, has showed better catalytic activity. This result finding is in agreement with a study reported by Mohammed and Jabbar (2015), their study disclosed that homogeneous catalyst gave better performance than heterogeneous catalyst in esterification reaction of alcohol such as methanol with fatty acid with lower catalyst loading needed and higher product obtained. Other than that, generally homogeneous catalyst gave higher conversion than heterogeneous catalyst. This may be due to better contact between reactants and homogeneous catalyst in the entire volume of reaction, while for heterogeneous catalyst, the reactants have limited contact on the active sites only (Mohammed and Jabbar, 2015). Therefore, $p$-TsOH will be used for the next study.

TABLE 2. ACID VALUE (AV) OF PRODUCT AND AMOUNT OF WATER COLLECTED FOR EACH CATALYST

\begin{tabular}{|c|c|c|}
\hline Type of catalyst & $\begin{array}{l}\text { Final AV mg } \\
\left(\mathrm{KOH} \mathrm{g}^{-1}\right)\end{array}$ & $\begin{array}{c}\text { Amount of water } \\
\text { collected } \\
(\text { theoretical } \\
\text { amount }=5.4 \mathrm{ml})\end{array}$ \\
\hline Amberlyst A-46 & 28.11 & 4.7 \\
\hline Amberlyst A-15 & 12.03 & 5 \\
\hline$p$ - $\mathrm{TsOH}$ & 1.98 & 5.3 \\
\hline Montmorillonite & 156.39 & 3.5 \\
\hline
\end{tabular}

Note: All experiments were carried out at $140^{\circ} \mathrm{C}$ for $8 \mathrm{hr}$ using $8 \%$ catalyst amount.

$p$-TsOH - $p$-toluene sulphonic acid.
Effect of catalyst loading. The amount of catalyst used is a crucial economics factor for successful industrial application. Therefore, a study on the effect of using various percentage of $p$-TsOH ranging from $3 \%, 5 \%, 8 \%, 10 \%$ and $12 \%$ based on weight percent of Gly was carried out. As shown in Figure 5, reactions conducted with $8 \%$ or higher catalyst loading gave AV of less than $1 \mathrm{mg} \mathrm{KOH} \mathrm{g}^{-1}$. Further loading of $p$-TsOH up to $12 \%$ resulted in a marginal decrease of AV. An increase in the catalyst loading leads to an increase of the reaction rate due to an increase in the total number of active catalytic sites (Delgado et al., 2007). These observations will help to determine the optimum amount of $p-\mathrm{TsOH}$ required to make the process viable with maximum composition of Gt-LE formed. Further experiments were conducted with $8 \%$ of catalyst loading to study other operating conditions.

Molar ratio between Gly and LA. The effects of reactant mole ratios on the formation of Gt-LE were investigated. The mole ratios of Gly:LA were varied from 1:3, 1:4, 1:5 and 1:6 mole while keeping the rest of the experimental conditions similar. The results obtained are presented in Figure 6. Generally, the composition of Gt-LE increased when the reactant mole ratio was increased. This is made evidence by the increase of Gt-LE composition from $21.7 \%$

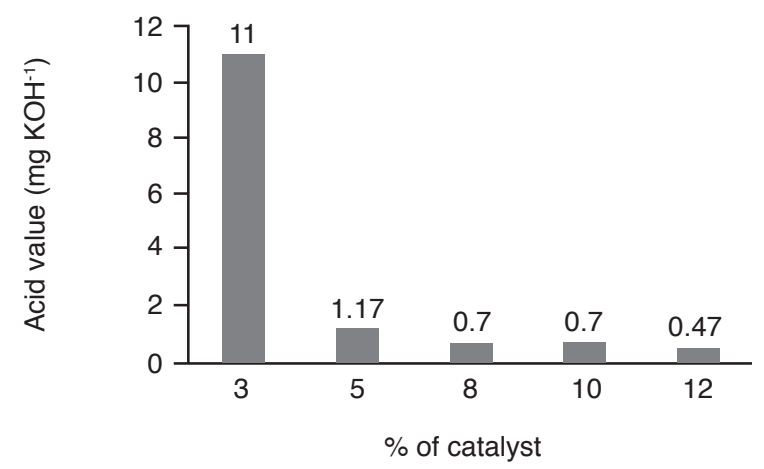

Figre 5. Effect of catalyst loading on acid value of product. Reaction was carried out at $140^{\circ} \mathrm{C}$ for $8 \mathrm{hr}$ using 1:3 (Gly:LA) mole ratio. 


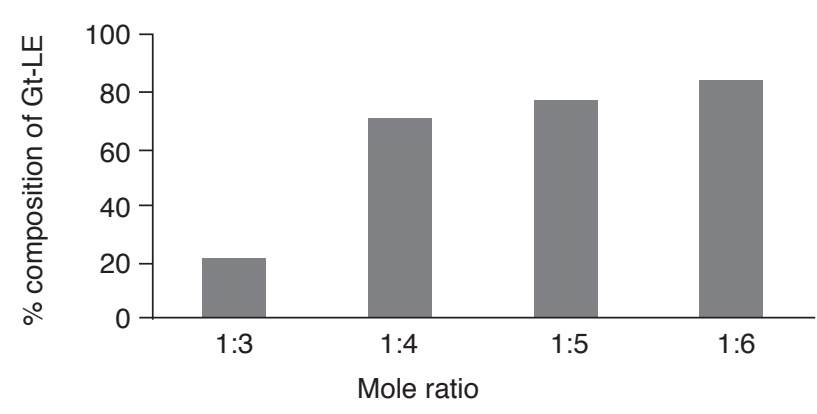

Figure 6. Effect of mole ratio between glycerol and levulinic acid on the reaction on the formation of glycerol trilevulinate (Gt-LE).

to $84.5 \%$ when the mole ratio between Gly:LA was increased from 1:3 to 1:5. The analysis result shows that mole ratio of 1:6 gave the highest percent composition of Gt-LE. According to Le-Chatelier's principle (Clark, 2013) in a chemical reaction, excess amount of one reactant drives the reaction in the forward direction. Therefore, mole ratio of 1:6 (Gly:LA) is preferred to maximise the formation of Gt-LE for the next study.

Effect of catalyst loading using mole ratio of $1: 6$ (Gly:LA). The effect of $p$-TsOH catalyst loading on the reaction at mole ratio of 1:6 (Gly:LA) was studied. The catalyst amount was varied from $1 \%$ to $5 \%$ and the result was compared with $8 \%$ catalyst. Figure 7 shows that reaction conducted with lower amount of catalyst $(1 \%-5 \%)$ have yielded lower percent composition of Gt-LE as compared to reaction conducted with $8 \%$ p-TsOH which generated $84.5 \%$ of Gt-LE. The result revealed that higher amount of catalyst loading will generate product with higher composition of the desired Gt-LE. The results prove that the optimal $p$-TsOH loading is $8 \%$.

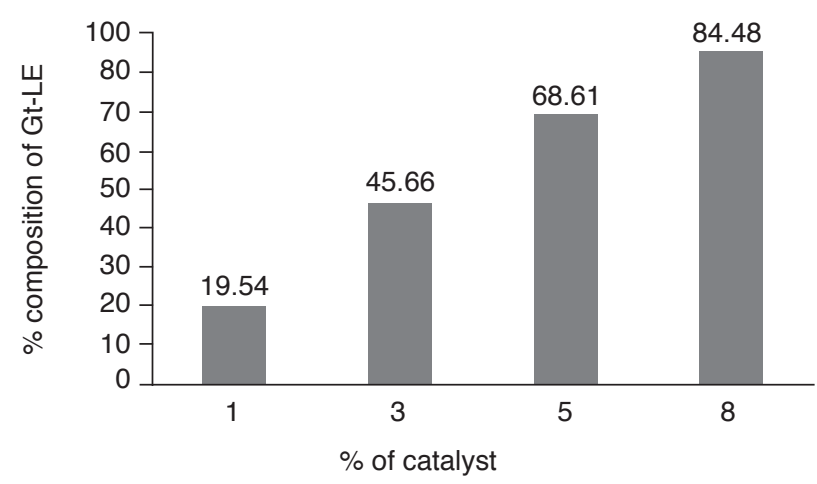

Figure 7. Effect of catalyst loading on the formation of glycerol trilevulinate $(G t-L E)$ when mole ratio of glycerol to levulinic acid was at 1:6.

Effect of reaction time on the product. The reaction was conducted at mole ratio of 1:6 (Gly:LA) with $8 \% p$-TsOH catalyst loading. The reaction was monitored by $\mathrm{AV}$ analysis and by measuring the amount of water collected from the reaction in the Dean and Stark apparatus (Figure 8). The reaction was conducted for $8 \mathrm{hr}$. It was observed that the theoretical amount of water to be collected (5.4 $\mathrm{ml}$ ) was achieved after $5 \mathrm{hr}$ of reaction. After $7 \mathrm{hr}$ of reaction, the amount of water increased to $5.6 \mathrm{ml}$ and remained the same after $8 \mathrm{hr}$ of reaction. The excess amount of water obtained may come from moisture in Gly. Result for AV analysis as shown in Figure 9 also supports this finding. After $5 \mathrm{hr}$ of reaction, the AV had reached a plateau. Therefore, the optimum reaction time for above corresponding reaction parameter was $5 \mathrm{hr}$.

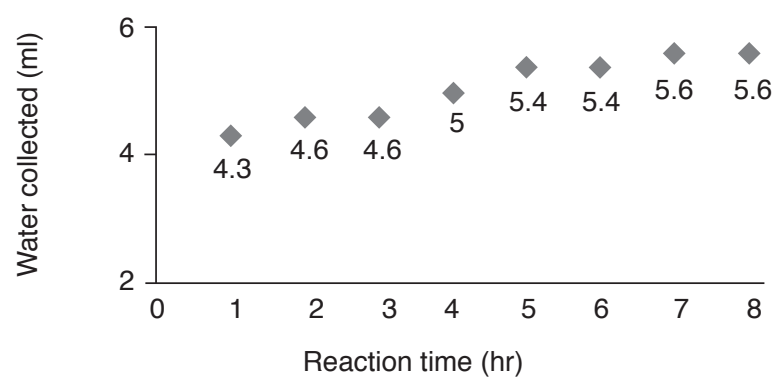

Figure 8. Amount of water collected against time for reaction condition of $8 \% \mathrm{p}$-tolune sulphonic acid (p-TsOH) with 1:6 mole ratio of Gly:LA at $140^{\circ} \mathrm{C}$ reaction temperature.

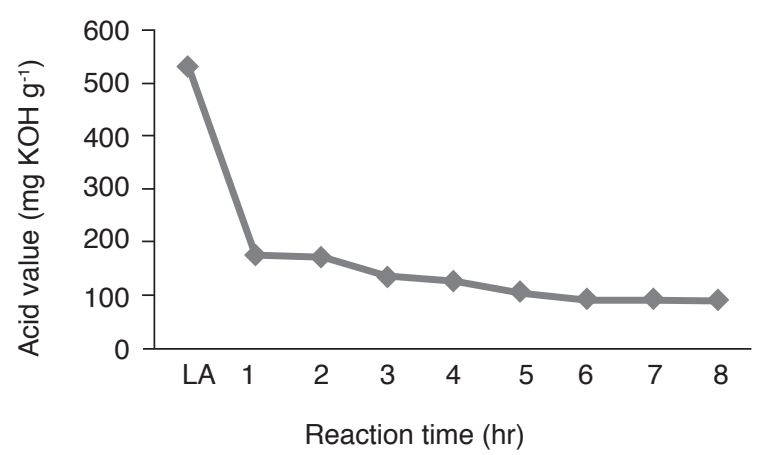

Figure 9. Effect of reaction time on acid value for reaction condition of 8\% $\mathrm{p}$-tolune sulphonic acid ( $\mathrm{p}-\mathrm{Ts} \mathrm{OH})$ with 1:6 mole ratio of Gly:LA at $140^{\circ} \mathrm{C}$ reaction temperature.

\section{Characterisation of Gt-LE}

FTIR spectra. FTIR spectra of both Gly and LA were compared with the product in order to prove that the esterification reaction between Gly and LA has taken place. In the FTIR spectrum (Figure 10), the absorption band at $1702 \mathrm{~cm}^{-1}$ assigned to $\mathrm{C}=\mathrm{O}$ stretching of ketone carbonyl group of LA has shifted to $1714 \mathrm{~cm}^{-1}$ and the presence of ester carbonyl peak at $1736 \mathrm{~cm}^{-1}$ indicated the esterification between Gly and LA has occurred. Other than that, the C-O stretching of carboxylic acid of LA at $1162 \mathrm{~cm}^{-1}$ has shifted to a sharp peak at $1147 \mathrm{~cm}^{-1}$, which affirmed the esterification reaction has transpired. 


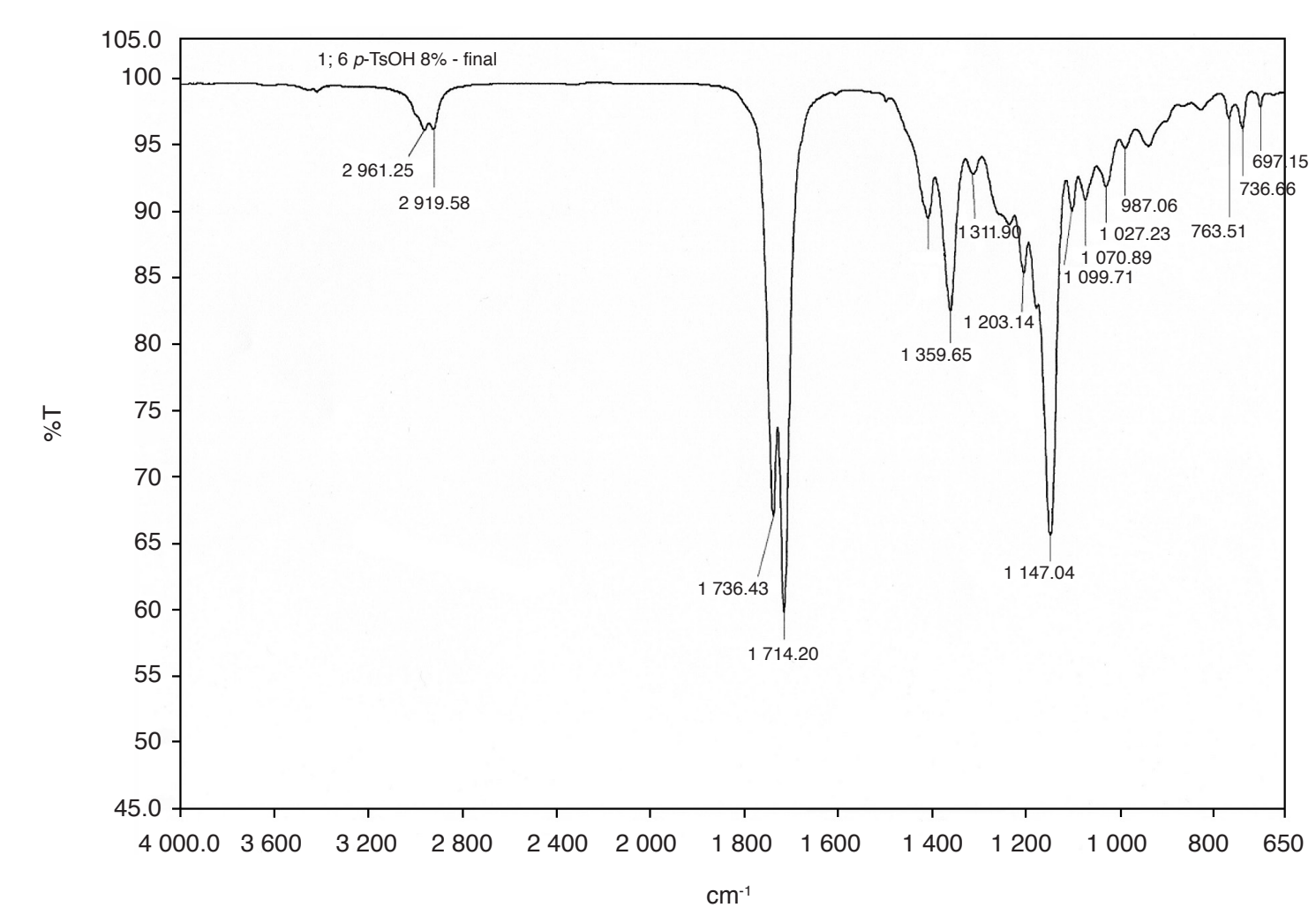

Figure 10. Fourier transform infrared (FTIR) spectrum of glycerol trilevulinate (Gt-LE) obtained from p-tolune sulphonic acid (p-TsOH)-catalysed esterification between glycerol (Gly) and levulinate acid (LA) at 1:6 mole ratios and at $140^{\circ} \mathrm{C}$ for $8 \mathrm{hr}$.

${ }^{1} \mathrm{H}$ and ${ }^{13} \mathrm{C}$ NMR analysis. Figure 11 shows the ${ }^{1} \mathrm{H}$ and ${ }^{13} \mathrm{C}$ NMR spectra of Gt-LE. The chemical shift at $2.173 \mathrm{ppm}$ in ${ }^{1} \mathrm{H}-\mathrm{NMR}$ spectrum (Figure 11a) correspond to the terminal methyl groups $\left(-\mathrm{CH}_{3}\right)$ of the levulinate ester chain. The protons attached adjacent to ketone-carbonyl and ester-carbonyl were featured at $2.748 \mathrm{ppm}$ and $2.586 \mathrm{ppm}$ respectively. Peaks at 4.173-4.252 ppm and 5.223-5.240 ppm were related to the protons of $-\mathrm{CH}_{2}$ - and central carbon in the glyceride unit correspondingly. For the ${ }^{13} \mathrm{C}-\mathrm{NMR}$ spectrum (Figure 11b), the carbonyl groups (-CO-) of ketone and ester appeared at 206 and 172 ppm, respectively. The glyceride carbons present in $-\mathrm{CH}_{2}-$ groups and central carbon can be observed at 62 and $69 \mathrm{ppm}$, respectively. In addition, peaks at $27 \mathrm{ppm}$ and $37 \mathrm{ppm}$ correspond to the $-\mathrm{CH}_{2}$ - group next to ester and ketone group, respectively. While peak 29 ppm relates to $-\mathrm{CH}_{3}$ group of the levulinate ester.

GC of Gt-LE. The formation of Gt-LE was confirmed qualitatively via GC analysis. The GC chromatogram confirmed that the synthesised product contains high percent composition of GtLE $(85 \%)$ as represented by a peak at retention time at $22.12 \mathrm{~min}$ (Figure 12). The chromatogram also indicated the existence of two other minor products with low percent composition namely Gm-LE and Gd-LE, which appeared at $13.904 \mathrm{~min}$ and $17.897 \mathrm{~min}$.

\section{CONCLUSION}

Non-catalytic reaction conducted at $140^{\circ} \mathrm{C}$ for $5 \mathrm{hr}$ yielded product with $63.14 \%$ composition of total glycerol levulinate ester (GLE). On the other hand, $p$ - $\mathrm{TsOH}$ the heterogeneous catalyst was the preferred catalyst for catalysed reaction as compared to montmorillonite, Amberlyst-15 or Amberlyst-46. From this study, Gt-LE was successfully synthesised using $p$ - $\mathrm{TsOH}$ as catalyst at $140^{\circ} \mathrm{C}$ for $5 \mathrm{hr}$. The best mole ratio to obtain high composition of Gt-LE without having to go through cumbersome purifying process was 1:6 with $8 \%$ catalyst loading. The GC, FTIR and NMR analysis confirmed that the synthesised product contains Gt-LE with the yield of $65 \%$ and $85 \%$ purity. The optimised reaction procedure to synthesise GtLE may gave opportunity to industrial player in specialty chemical to produce at larger scale where this indirectly increase the uses of glycerol and chemical derived from biomass.

\section{ACKNOWLEDGEMENT}

The authors wish to thank the Director-General of MPOB for permission to publish this article and for funding of this research project. 

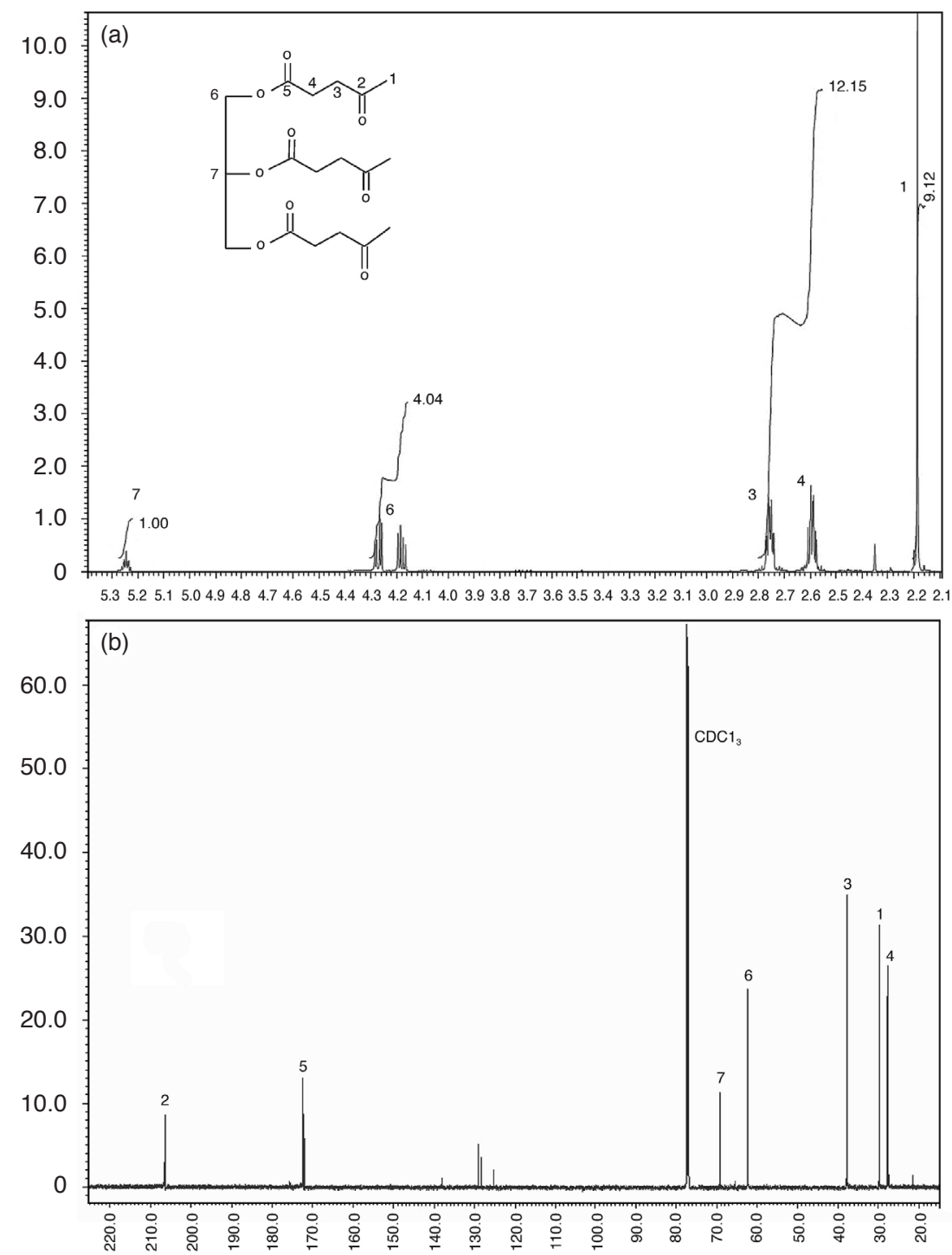

Figure 11. The ${ }^{1} \mathrm{H}$ nuclear magnetic resonance (NMR) (a) and ${ }^{13} \mathrm{C}-\mathrm{NMR}$ (b) spectrum of glycerol trivulinate (Gt-LE) obtained from p-toluene sulphonic acid ( $\mathrm{p}-\mathrm{Ts} \mathrm{OH}$ )-catalysed esterification between glycerol (Gly) and levulinate acid ( $\mathrm{LA}$ ) at 1:6 mole ratios and at $140^{\circ} \mathrm{C}$ for $8 \mathrm{hr}$.

FID1 B, (NIKMEI17INIK00019.D)

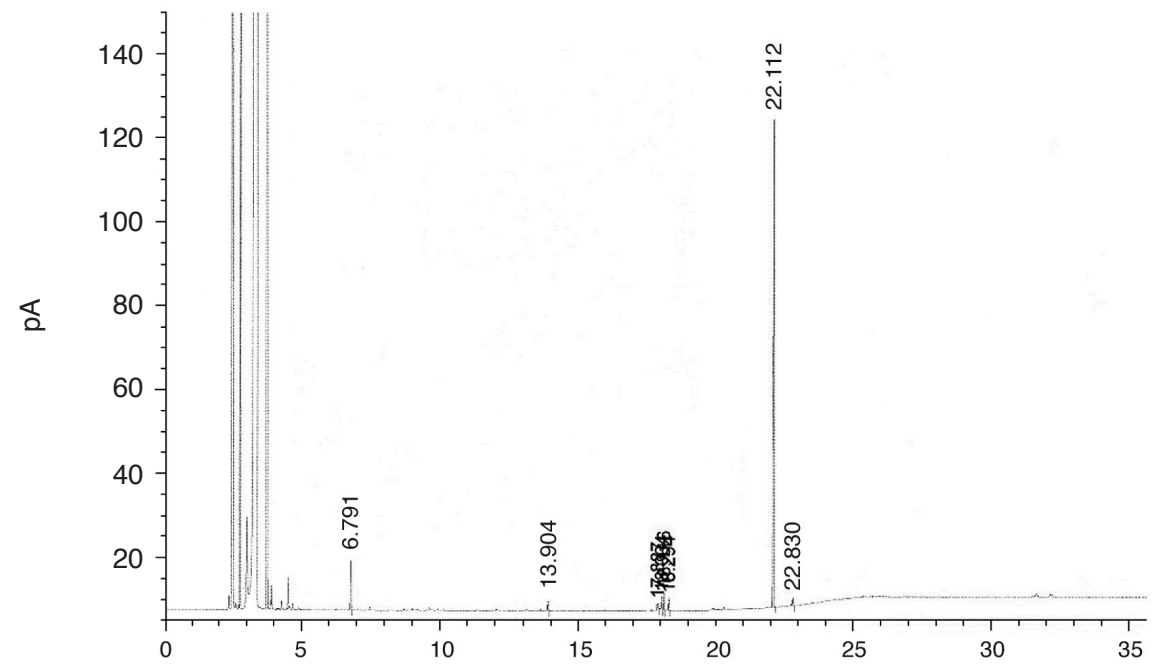

Figure 12. Gas chromatography (GC) chromatogram of glycerol trivulinate (Gt-LE) obtained from p-toluene sulphonic acid (p-TsOH)-catalysed esterification between glycerol (Gly) and levulinate acid (LA) at 1:6 mole ratios and at $140^{\circ} \mathrm{C}$ for $8 \mathrm{hr}$. 


\section{REFERENCES}

Amarasekara, A S and Hawkins, S A (2011). Synthesis of levulinic acid-glycerol ketal-ester oligomers and structural characterization using NMR spectroscopy. European Polymer J., 47: 2451-2457.

Ashworth, I W; Bush, E; Chan, L C; Cherryman, J; Cox, B G; Muir, J; Korupoju, S R and Keshwan, J (2012). Where has my acid gone? Understanding the self-catalyzed esterification of maleic acid in methanol during salt formation. Organic Process Research \& Development, 16: 1646-1651.

ASTM (2016). Standard Test Method for Pressure Mottling and Blocking Resistance of Organic Coatings on Metal Substrates. West Conshohocken, PA, USA: ASTM International. 3 pp.

ASTM (2017). Standard Test Methods for Scrub Resistance of Wall Paints. ASTM International. 4 pp.

Bloom, P D (2007). Levulinic acid ester as rective plasticizers and coalescent solvents. French patent application 2007094922A2.

Bozell, J J; Moens, L; Elliott, D C; Wang, Y; Neuenscwander, G G; Fitzpatrick, S W; Bilski, R J and Jarnefeld, J L (2000). Production of levulinic acid and use as a platform chemical for derived products. Resources, Conservation and Recycling, 28: 227-239.

Clark, J (2013). Le chatelier's principle. https:// www.chemguide.co.uk/physical/equilibria/ lechatelier.html, accessed on 26 June 2018.

Da-Wei, W; Hong-Yan, L; Run-Jie, C; Ze-Zhong, M; Tao, C; Ge-Fei, H; Wen-Chao, Y and Guang$\mathrm{Fu}, \mathrm{Y}$ (2015). Design, synthesis and herbicidal activity of novel quinazoline-2,4-diones as 4-hydroxyphenylpyruvate dioxygenase inhibitors. Pest Management Science, 71: 1122-1132.

Dange, P N and Rathod, V K (2017). Equilibrium and thermodynamic parameters for heterogeneous esterification of butyric acid with methanol under microwave irradiation. Resource-efficient Technologies, 3: 64-70.

Delgado, P; Sanz, M T and Beltrán, S (2007). Kinetic study for esterification of lactic acid with ethanol and hydrolysis of ethyl lactate using an ion-exchange resin catalyst. Chemical Engineering J., 126: 111-118.

Girisuta, B and Heeres, H J (2017). Levulinic acid from biomass: Synthesis and applications. Production of Platform Chemicals from Sustainable Resources (Fang, Z; Smith, J R L and Qi, X eds.). Springer, Singapore. 475 pp.
Go, A W; Tran Nguyen, P L; Huynh, L H; Liu, Y-T; Sutanto, S. and Ju, Y-H (2014). Catalyst free esterification of fatty acids with methanol under subcritical condition. Energy, 70: 393-400.

Kenar, J A (2007). Glycerol as a platform chemical: Sweet opportunities on the horizon? Lipid Technology, 19: 249-253.

Khan, A S; Man, Z; Bustam, M A; Nasrullah, A; Ullah, Z; Sarwono, A; Shah, F U and Muhammad, N (2018). Efficient conversion of lignocellulosic biomass to levulinic acid using acidic ionic liquids. Carbohydrate Polymers, 181: 208-214.

Kushairi, A; Loh, S K; Azman, I; Hishamuddin, E; Ong-Abdullah, M; Izuddin, Z; Razmah, G; Sundram, S and Parveez, G K A (2018). Oil palm economic performance in Malaysia and R\&D progress in 2017. J. Oil Palm Res. Vol. 30 (2): 163-195.

Kushairi, A; Singh, R and Ong-Abdullah, M (2017). The oil palm industry in Malaysia: Thriving with transformative technologies. J. Oil Palm Res.Vol. 29 (4): 431-439.

Lam, M K; Lee, K T and Mohamed, A R (2009). Life cycle assessment for the production of biodiesel: A case study in Malaysia for palm oil versus Jatropha oil. Biofuels, Bioproducts and Biorefining, 3: 601-612.

Lindstedt, S; Holme, E; Lock, E A; Hjalmarson, O and Strandvik, B (1992). Treatment of hereditary tyrosinaemia type I by inhibition of 4-hydroxyphenylpyruvate dioxygenase. The Lancet, 340: 813-817.

Mohammed, W T and Jabbar, M F A (2015). Comparison between homogeneous and heterogeneous esterification reactions for biodiesel production using reactive distillation. International J. Current Engineering and Technology, 5: 3439-3447.

Pöpken, T; Götze, L and Gmehling, J (2000). Reaction kinetics and chemical equilibrium of homogeneously and heterogeneously catalyzed acetic acid esterification with methanol and methyl acetate hydrolysis. Industrial \& Engineering Chemistry Research, 39: 2601-2611.

Rackemann, D W and Doherty, W O (2011). The conversion of lignocellulosics to levulinic acid. Biofuels, Bioproducts and Biorefining, 5: 198-214.

Ramli, N A S and Amin, N A S (2014). Catalytic hydrolysis of cellulose and oil palm biomass in ionic liquid to reducing sugar for levulinic acid production. Fuel Processing Technology, 128: 490-498. 
Sanz, M T; Murga, R; Beltrán, S; Cabezas, J L and Coca, J (2002). Autocatalyzed and ion-exchangeresin-catalyzed esterification kinetics of lactic acid with methanol. Industrial \& Engineering Chemistry Research, 41: 512-517.

Tiong, Y W; Yap, C L; Gan, S and Yap, W S P (2018). Kinetic study on oil palm biomass conversion to levulinic acid via indium trichloride-ionic liquids. $2^{\text {nd }}$ International Conference on Energy and Environmental Science. Kuala Lumpur.
Unnithan (2018). Palm biodiesel industry Navigating through the storm. Lauric Oils Price Outlook Conference \& Exhibition. Kuala Lumpur.

Werpy, T; Petersen, G; Aden, A; Bozell, J; Holladay, J; White, J; Manheim, A; Eliot, D; Lasure, L and Jones, S (2004). Results of screening for potential candidates from sugars and synthesis gas. Top Value Added Chemicals from Biomass. Department of Energy, Washington DC, USA. 76 pp. 